\title{
Cohesion: Structuring Content Through Textual Features in Kenyan Sign Language (KSL) Formal Discourse
}

\author{
Jefwa G. Mweri \\ Department of Kiswahili \& Kenyan Sign Language Research Project, Faculty of Arts University of Nairobi, Kenya
}

Copyright $(\mathcal{C} 2015$ by authors, all rights reserved. Authors agree that this article remains permanently open access under the terms of the Creative Commons Attribution License 4.0 International License

\begin{abstract}
Content in formal or planned discourse can be "structured through the content of its proposition" - that is through the use of an organizational structure that denotes planned discourse. This paper discusses a lecture delivered in KSL by a deaf person. The lecture under analysis was divided into episodes or in some form of schema that included focal, developmental and closing episodes. This organizational structure though contributing to cohesion in the lecture is not the focus of this paper. The focus of this paper is to examine how cohesion in formal KSL discourse is structurally achieved though textual features that reflect transition boundaries between episodes and link episodes together" (Roy 1989). Cohesion in discourse refers to the links and connections that unite the elements of a discourse or text. It is the links that hold a text together to give it meaning. These connections involve lexical and grammatical devices. To be able to achieve their informational, social functions, lectures, use different cohesive devices. Those discussed in the paper to show their cohesive nature include: New topic transition markers, Signalers that introduce new items in the time series, Chronological signalers, Signalers that express relations between facts, Signalers that introduce items in the same series, Quantity signalers, Signalers that introduce example or particularization of what has just been said and Signalers that indicate a restatement of what has just been said (repetition).
\end{abstract}

Keywords Structuring Content through Textual Features in KSL

\section{Introduction}

There are some types of discourses in which the outcome or the accomplishment of communication can, if all goes well for the sender, be closely identified with a plan, and prior to that a set goal or set of goals, which the sender has in mind. This kind of discourse entails careful planning since the intended effects are envisaged and the means to achieve this reviewed, evaluated, and decided upon and implemented. This is true of planned discourse which is seen as having "goals and plans." Planned discourse therefore is a non instinctive discourse type that tends to be more complex since it involves forethought, design and organization; it thus relies on syntax to relay semantic information.

The problem addressed in this study emanates from a gap in Sign Language, especially KSL research. While research in spoken languages is advanced at all levels, research on sign language (SL) generally started in earnest in 1960 after the pioneering work of William C. Stokoe [1]. Since Ferdinand de Saussure [2], spoken language research was on structure of language before that the concentration of linguistic scholarship was on Historical and comparative philology (read Linguistics). Early research on SL too tended towards the structural aspects of the language.

Research on SL discourse in particular started in the 1980s. Understandably, even the pioneering research on discourse done in America also tended towards aspects of structure of conversation and exchange of talk. Roy [3] says Studies in America Sign Language (ASL) mainly focused on discourse macro features such as:

a) Turn taking

b) Linguistic functions of non-verbal behaviours

c) Utterance boundaries

The 1980s also saw serious attempts towards discourse analysis per se. Studies from this period dealt with conversational differences in greetings, on-going conversation, leave taking between deaf and hearing conversation and SL of deaf children etc.

Most of the above mentioned research was done in America and Europe. Thus research in SL in these countries is advanced at both structure and discourse levels. This however is not the case in Africa in general and Kenya in particular. The little research that has been undertaken in KSL also tended towards structure or is on some socio-linguistic aspects of KSL. Research in discourse analysis on KSL is non-existent (to the best of our knowledge).

This study is thus an attempt to fill in the lacuna or knowledge gap that exists due to limited research on KSL in general and non-existent research on use of language sensitive to situation in this case formal situation in KSL in particular. Bearing in mind that language use is usually 
sensitive to its context of situation, and that different situations therefore require us to use language differently, this study attempts to determine how contextual factors influence KSL use. To do this, we examine how KSL user's use it in planned (formal) discourse by abstracted the dialogical or identifying features of KSL as used in planned discourse (lecture) and its motivational factors.

This study thus addressed itself to the following questions:

i. What are the discourse features that are used in planned discourse in KSL, specifically in a lecture?

ii. What cohesive devices are likely to be used in formal KSL specifically in a lecture?

iii. How do these cohesive devices assist in achievement of cohesion in planned discourse in KSL?

\subsection{Review of Literature}

One of the most vital works on discourse analysis in SL is The Sociolinguistics of the Deaf Community, Lucas, 1989 [4]. In this work, a paper by Roy on "Features of Discourse in An American Sign Language Lecture" is of great significance to our study. Roy (ibid) examines the features of discourse that occur in a lecture given in American Sign Language (ASL) and records basic findings which touch on the surface of the complex nature of discourse. Basic as these findings may be, we found them very important to our study. Roy's study for example identified the following as categories of discourse markers in ASL:

a) Head nodes

b) The sign OK and ANYWAY,

c) The lexical sign NOW, NOW THAT etc.

The study also identified non-manual features such as different head orientations, change of eye gaze etc. or what is called "analogic persuasion." All these had a bearing on our study since they helped by giving us some indication of the elements of discourse we examined. Roy's study also examines a lecture and though the language of study of this text is ASL while the language in the present study is KSL, this text inspired us to examine a lecture in KSL.

Another very important paper in the same text is that by Zimmer (Lucas, Op.cit.) entitled "Towards a Description of Register Variation in ASL". This paper describes the use of language sensitive to situational factors. The research videotaped native ASL users in three different situations:

a) A formal lecture in an academic setting

b) An informal talk

c) A television interview

The tapes were transcribed and compared to discover potential language variations and the findings support the notion that language users in general and ASL users in particular vary their language according to situation of use.

Zimmer (ibid), in discussing the data, reviews different models of register variation in general and those of register variation in ASL in particular and analyzes different processes that manifest themselves in situational use of SL i.e. phonological differences, lexical and morphological differences and differences in syntax and register organization. Though Zimmer examines Intra textual register variation in an academic lecture it was essential in as far as our study is also on a lecture. This paper was essential for our study given that very little literature is available in terms of discourse analysis in SL generally and KSL in particular. Though the study was conducted on ASL, a sign language very different from KSL, the paper helped us gain insight into discourse analysis in SL in general.

Other works that have relevance to this study though they are on other sign languages include: Kavanagh and Cuttings [5]. The role of speech in Language. In this text, a paper by Klima and Bellugi (op.cit) on "Aspects of sign language and its structure" was important. Though based on American Sign Language, it did generally shed some light on aspects of sign language structure. In the same work, Kavanagh and Cuttings (op.cit), Janellen's paper on "Encoding information in sign language." was also relevant to our study, though it is based on ASL.

The text by Siegmund and Vollahber [6], Current Trends in European Sign Language Research, deals with diverse issues such as sign language history, aspects of bilingualism, sign language grammar and methodology. The section on methodology was the most important to us since it also deals with sign writing and transcription. Jovison's (ibid) article on "Analysis and Liner transcription of Sign Language Discourse" was of particular significance since among other things it contains some types of forms and transcriptions, which we used in our analysis of our data.

Another important text to our study is that by Ochs and Bennett, [7] Discourse Across Time and Space. Of particular interest to us is the paper by Elinoor (op cit.) entitled "Why look at unplanned and planned discourse" in which unplanned and planned discourse are discussed. Though the concern is not primarily on SL as such, the text is useful reading since the author outlines the characteristics of both planned and unplanned discourse. The study reveals that planned discourse is more complex since it involves fore thought, design and organization while unplanned discourse relies heavily on immediate context to express thought. We have in this research followed the same line of investigation as that of Ochs and Bennett, though our focus is on one form of planned discourse - a lecture.

Works done on KSL to the best of our knowledge are basically on structure and other related issue. No attempt has been made on studying discourse analysis in KSL. The most significant structural description on KSL was done by Akach [8]. In an unpublished M.A. dissertation, Akach examined "sentence types in KSL". Using a structural approach, he identifies and analyses the following types of sentences: Declaratives, Asserted declarative statements, Interrogative sentences, Yes/No questions, Wh- questions, Conditional sentences, topicalization, Imperative sentences and Rhetorical sentences. Though Akach's study is not on discourse analysis, it was important to us since it is done on the language of our study. Similarly, some sentence types 
discussed in Akach's study also characterize certain types of discourse. In unplanned discourse, some degree of flexibility was detected in the formation strategies for these sentence types.

Scholarly works on KSL but which have no immediate relevance to our study but helped in shedding some light on several aspects of KSL include: Akach, The Kenyan sign Language Dictionary. Revised by Mweri [9]. Okombo's, "Obstacles in the development of African Sign Languages"; "Linguistics and the Liberation of the Kenyan Deaf: Research Agenda for Sign Language Developers"; "African Languages: Will sign Language have better luck? "Bilingualism in the schools for the Deaf." [10] Okombo and Akach [11] "Language convergence and wave phenomena in the growth of a National Sign Language in Kenya."

More recently, other works on KSL include: Mweri's [12] "Diversity in Education; Respect for Language Minorities the case for Kenyan sign Language as a medium of Instruction in schools for deaf in Kenya"; "Signs and meaning, diversity in language use, equivalences and cultural untranslatability; "Sign Language Interpreter Training in Kenya."; Structural borrowing: The case of Kenyan sign Language (KSL) and Kiswahili Contact Signing; 'Complexities and Challenges of interpretation in the third world: The Kenyan case.'

\section{Methodology}

In this paper, the socially recognizable event under analysis is a lecture (formal). The lecture is viewed in relation to particular situations, purpose or levels of formality bearing in mind that the choice of register can be affected by factors such as; setting, topic and relationship between speakers. In this paper, such factors are analyzed. The data for this research was recorded from a lecture given by a deaf person Mr. Washington Akaranga a senior researcher with KSLRP who is deaf and therefore a native user of KSL. Mr. Akaranga's choice was deliberate and justified by his long experience in KSL research, together with his native speaker status he was thus in a better position to verify the KSL data collected. The setting was in a lecture hall and the lecture was conducted in KSL and the audience was a group of fourth year Bachelor of Education students taking psycholinguistics in Kiswahili at Kikuyu campus of the University of Nairobi.

The students were about 20 in number and of mixed gender. The lecture took about 1 hour and fifteen minutes which is within the normal lecture period of two hours. The topic of the lecture was "KSL and the lives of Deaf Kenyans." Interpretation from KSL into English and vis- a-vis was done by Ms Mary Njoki a competent KSL interpreter. The text under analysis was transcribed from spoken interpretation of the lecture by Mary Njoki.

The participants in the lecture were selected by virtue of the fact that they were student of psycholinguistics and one of the topics they were learning was language acquisition and they had covered the topic acquisition of sign Language but most of them knew little about the deaf. This lecture was a way of letting them come face to face with a language different from the one they are used to and to make them understand that language acquisition is not about spoken Language.

Data collection was by video recording and participant observation - our deaf research assistants i.e. were responsible for most of the recording of the data while the research was a non-participant observer though a fluent KSL user himself.

\section{Data Elicitation Techniques}

The following methods of data elicitation were used in this research. The collection of data took a multiple- technique approach. The techniques used include:

i) Introspective evidence

ii) Analytical evidence

iii) Participant observation

\section{i) Introspective evidence}

Data was collected through introspection where the researcher relied on his near native speaker's competence in inferring important linguistic structures of KSL. Though doubts have been raised on the ability of a researcher to personally generate data and draw conclusions from the same, introspection however has come to be an acceptable since it has been used in linguistics to discover facts about language and also contribute deeper theoretical understanding. To check on the existence of biases on the part of the researcher, the data was cross checked with native speakers of the language.

\section{ii) Analytical evidence}

This being a qualitative research aimed at gathering an understanding of human behaviour and the reasons for such behaviour- that is language use in formal situations in KSL, the data for analysis was collected variably. For the planned discourse- the lecture, deaf research assistant's video recorded its formal use in a lecture.

\section{iii) Participant observation}

Participant observation occurs with the researcher playing an established participant role at the scene of study. It is important to distinguish between participant observation and non participant observation. In the later, the researcher plays a significant role which is not established in the sense that he is a complete observer. In this research, the researcher was a non participant observer in the lecture.

\section{Data analysis}

The following is what our intuitive data upon which the analysis is based consisted of:

1. The discourse features that the deaf are likely to employ in formal discourse. 


\section{The motivational factors behind such choice.}

The video tapes containing the lecture for students, was transcribed and analyzed to discover the discourse features used in planned and any situational factors that trigger the use of those discourse features in planned discourse in KSL. It is important to note that KSL like most signed languages does not have a written format. The following conventions are used during the glossing; a single slash / stands for a "comma" while a double slash // stands for a "full stop."

It is important to note that in this paper, in the analysis of data, KSL text is written in capital letters to distinguish it from text or words in English or any other language for that matter. Thus in the examples given, KSL text is written in capital letters and below it we give a translation in English of the KSL sentences used. For example:

\section{KSL: ME HOME GO}

ENG: I am going home

The words ME, HOME and GO are use to gloss KSL signs that represents signs and not words in English.

\section{Theoretical Framework}

This study is not a theory testing study, it is therefore not based on any particular theory but instead uses a theoretical framework as its descriptive tool to guide it in terms of what it shall measure or look out for. A theoretical framework is a collection of interrelated concepts just like a theory but in a theoretical framework the concepts are not well worked out. The theoretical framework will act as guide or plan for analysis. A theoretical framework makes use of the interrelated concepts in a new way to explain the relationship between those concepts. Since a theoretical framework interrelates to various theories it allows for an eclectic approach in the analysis of data.

The analysis of data in this paper is therefore guided by an eclectic approach. The discourse analysis approach we used is the one propagated by such analysts as Halliday and Hasan [13], they examined cohesion and presented taxonomy of various types of cohesive ties.

This research though done on a visual language KSL as compared to English used by Halliday and Hasan which is an audio based language benefited a lot from their taxonomies. Their taxonomy is relevant in the examination cohesion KSL discourse. Halliday [14] also proposed a model for characterizing a speech situation which is useful to our analysis. This model consists of the field of discourse, the mode of discourse, the tenor of discourse and a fourth category that was added by Gregory and Carroll - the functional tenor. Halliday's model and the addition by Gregory and Carroll (op.cit.), is used in our data analysis to characterize speech situation under analysis for example through the field of discourse, we were able to analyze the physical setting and social activities that surround and define a speech event in this case a planned speech event.

Other stylistic approaches to discourse analysis were adopted by analysts such as Joss [15]. Joos posits five styles in his model for the study of register variation. These styles are used by people in discourse and they range from least formal to most formal. They include: Intimate, casual, consultative, formal style and frozen. The Consultative style, which we view as an in-between the casual and formal style is useful for the analysis of both formal and informal discourse. In this case it's essential in our analysis of formal discourse. Similarly, formal and frozen styles are used in the analysis of planned discourse since they are styles used in formal situations.

Crystal and Davy [16] discuss factors that help determine language use. They mention three categories of features within their model that in part determine the type of utterances prescribed in particular situations: Province features, status features and modality features. These three features separately or combined cause speakers to follow expected conventions for a particular type of discourse in which they are involved.

The types of features they propose assisted us in the analysis of our data since they are (the proposed features) basically contextual factors and contextual use of language is what our research is all about. The different types of features mentioned assisted in determining for example whether occupation or profession can have a bearing on language use, whether participant's social status and the purpose served by an utterance can determine language use in planned KSL discourse.

Other models of register variation in sign language are based on American Sign Language (ASL). These models were based on what was proposed by Ferguson [17] when he identified separate spoken language varieties specified for function in a diaglossic situation. He identified high (H-) variety - used in formal situations and the low or (L) variety used in colloquial situations. Fischer [18] also discussed bilingual situations in which one language (SL) plays both roles i.e. H-role and L-role. Different features mark these two. Formal or H- role language, is slower paced, uses large signing space, more clear and more fully executed, uses twohanded variant of signs, non- manual grammatical features (NMG) have to appear with the manual ones. The informal (L-role) languages are characterized by: non-dominant hand deletion uses one handed variants, certain grammatical markers become more distinct in casual signing, and non-manual signals can appear without the manual components. Though based on ASL, these models (Ferguson, Fisher) were useful in the analysis of our KSL especially at the level of Formal discourse (H-variety).

\section{Discussion}

This paper therefore examines KSL use in formal settings. KSL use like most language usage is sensitive to situational factors in this case the formal setting of the lecture.

Language use sensitive to situation or context is called register. A register is sometimes known as style. 
The term register in some instances is used to mean formal or informal style. Other linguists use different terms for e.g. Halliday [19] uses the term tenor or style while Quirk et al [20] uses the term attitude. Style can also be classified as language varieties and can be viewed from the point of view of formality. Style or register in this case, is language used in a particular social setting and can be a socially recognizable event.

\section{According to Richards et al [21], a register is:}

a speech variety used by a particular group of people, usually sharing the same interests (e.g. stamp collectors, baseball fans). A particular register often distinguishes itself from other registers by having a number of distinctive words, by using words or phrases in a particular way ... and sometimes by special grammatical constructions.

Richards et al from the above, therefore see register as languages use that is socially constituted and recognized. Register involves formal or informal use of language by a speaker in a particular situation.

Joss [22] identifies five styles and purposes by which he views a register as style.

Frozen: Printed unchanging language such as Biblical quotations; often contains archaisms

Formal: One-way participation, no interruption. Technical vocabulary; "Fussy semantics" or exact definitions are important. Includes introductions between strangers.

Consultative: Two-way participation. Background information is provided - prior knowledge is not assumed. "Back-channel behaviour" such as "uh huh", "I see", etc. is common. Interruptions are allowed.

Casual: In-group friends and acquaintances. No background information provided. Ellipsis and slang common. Interruptions common.

Intimate: Non-public. Intonation more important than wording or grammar. Private vocabulary.

Following Joss, in this paper we take the view of register as differential use of language sensitive to situational factors and we shall try to abstract and explain the situational dynamics that control register with specific reference to planned discourse in KSL which falls under formal style in Joos' classification above.

Planned discourse entails careful planning since the intended effects are envisaged and the means to achieve this reviewed, evaluated, and decided upon and implemented. Planned discourse therefore is seen as having "goals and plans." And is a non instinctive discourse type. Compared to unplanned discourse for example, planned discourse tends to be more complex since it involves forethought, design and organization; it thus relies on syntax to relay semantic information. This paper examines different discourse features that characterize the language used in planned discourse in KSL specifically in a lecture. It analyses cohesive devices in KSL lecture by examining how cohesion is achieved in planned discourse in KSL.

\section{Cohesive Discourse Features in Planned Discourse Texts: The Case of a Lecture Delivered in KSL}

A lecture is viewed as a speech event in a particular social setting in this paper. Lectures in KSL form our research can be said to be schematized into three naturally occurring segments, which we also call episodes. Which, following Cook [23] are:

- An obligatory focal (or introduction) episode.

- An obligatory developmental episode.

- An obligatory closing episode.

\section{Focal episode}

This occurs at the beginning of the lecture where the speaker introduces him or herself. This is considered the obligatory focal episode. Thereafter the speaker can have two or more optional episodes. The obligatory focal episode and its following optional episodes are the opening remarks that serve as the introduction of the lecture. These opening remarks generally serve the all-important function of opening up the communication channels. This focal episode accords the speaker a chance for initial contextualization of information which is consistent with academic related lectures.

\section{Developmental Episode}

In the next episode, we have the obligatory developmental episode which can also be divided into several subtopics or optional developmental episodes. The obligatory developmental episodes together with its optional developmental episodes all constitute the body of the text (lecture) that is the section that mainly carries the content of the text.

\section{Closing episode}

The closing of the lecture is done systematically. It starts with an obligatory close this is followed by optional closing episodes which may include question/ answer optional closing episode which is characterized by question/answer pairs or by an initiation/response pattern. This obligatory closing episode conjointly with its optional episode combines to form the conclusion of the lecture.

The organizational structure above indicates planned discourse - in this case a lecture. Though lectures are formal and mostly monological, KSL lectures end up being more dialogical. The dialogical nature of a KSL lecture may be necessitated by the discourse topic and the size of the audience. This is what Crystal and Davy call 'Province' features - they relate an utterance to extra linguistic factors such as occupation or professional setting. Being a lecture, some other extra linguistic factors that determine its dialogical nature include the newness of the topic to the audience and how interested the audience is in the topic, these factors combined; turn a lecture in KSL into a highly interactive encounter. Even if this is the case, however, it is 
important to note that the lecture does not deviate from the principle of a formal lecture since it will be content-oriented and provided objective knowledge.

The structural organization of the lecture discussed in the schema above is just one way in which content is structured in discourse. This way it is "structured through the content of its proposition". However, according to Roy, content in discourse can also be structured though textual features that reflect transition boundaries between episodes and link episodes together."

The focus of this paper however, is not the structural organization of the lecture as discussed above but rather the textual features that mark transition from one subtopic to the next and features that link episodes together, that is, textual features which are also used organizationally in a lecture. These linguistic features are "kind of linguistic elements that are not a part of the content per se, but also do guide the listener on how to interpret information that they are hearing. These words and phrases are cohesive, structural devices that contribute to a listeners ability to distinguish between major and minor points, old versus new information, turns and shifts in the flow of the topic" Roy[24]. This way of structuring discourse is known as cohesion.

\section{Cohesion in a KSL Lecture}

Cohesion in discourse refers to the links and connections that unite the elements of a discourse or text. It is the links that hold a text together to give it meaning. These connections involve lexical and grammatical devices. Following Halliday [25], the lecture set in a lecture hall or the physical setting and social activity that surrounds and defines a speech event constitute the field of discourse for our research. Mode of discourse or the channel used is signed communication that was spontaneous in nature. Mostly monologic but with the question answer session during the closing episode it becomes dialogic. Who the participants are and the inter-personal dynamics involved in their relationship constitute the tenor of discourse which is about who is taking part, nature, status and roles that the participants play. In the lecture, we have the person giving the lecture who enjoys a high status given that he is a native user of KSL as compared to the audience composed mainly of hearing students. In the lecture we have both $1^{\text {st }}$ and $2^{\text {nd }}$ order roles. The deaf person giving the lecture can be extralinguistically defined as a teacher. The second order roles are defined in relation to the linguistic system in that the teacher is the informer and the audience is respondees. The language used in the lecture is what Gregory and Carroll classify in terms of functional tenor as language used to inform.

To be able to achieve their informational, social functions, lectures, use different cohesive devices. In KSL lecture, the following lexical features (Cohesion devices) were identified and will be discussed.

1. New topic transition markers

2. Chronological signalers
3. Signalers that express relations between facts

4. Signalers that introduce items in the same series

5. Quantity signalers

6. Signalers that introduce example or particularization of what has just been said

7. Signalers that indicate a restatement of what has just been said (repetition).

\subsection{New Topic Transition Markers}

These are lexical and grammatical devices used to mark transition into a new topic and in the process, they unite the elements of a discourse or text since they link and connect them. They are signalers that introduce new items in the time series.

They include:

NOW:

In KSL, NOW is signed with both hands with the lower arms bent both at elbow and wrist to make open palm pointing down facing the receiver with double movement as exemplified below:

Fig 1.

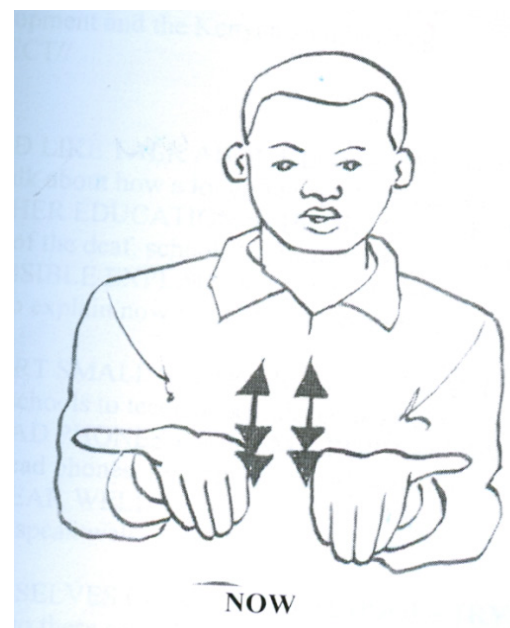

In KSL the use of NOW serves two main functions:

- As a marker of present time. Used this way NOW can be substituted with time reference today or at this time (it is used as a temporal marker).

- As a discourse marker indicating a "shift into a new topic or sub-topic as well as calling attention to what is coming next in the text" Roy [26]

These two functions of NOW are difficult to distinguish. However, Roy (Op.cit) identified some distributional and formal criteria that help to distinguish the two uses.

As a temporal marker, NOW indicated temporal relations between situations. In this way, it therefore functions as a proform of time especially present time. NOW as a temporal marker is signed the same way as NOW the discourse marker. However, the two occur in different positions in sentences. NOW as a discourse marker as we have seen above occurs in the utterance initial position. NOW can appear in this 
position too to start a discussion as in 1 (a) and (b) below. However, NOW as a temporal marker can occur in utterance initial position, utterance medial position and utterance final position.

This can be exemplified as follows:

\section{NOW ME HOME GO//}

Iam going home now

\section{SCHOOL BOSS HIMSELF}

\author{
The head teacher \\ PROPOSE NOW PARENTS ALL \\ proposed that all parents \\ MUST SCHOOL VISIT// \\ must visit School
}

\section{POSSIBLE ME EXPLAIN FROM}

It is possible for me to explain

TIME SCHOOL START HAPPEN

what happened since school

WHAT TILL NOW//

started up to now.

As a temporal marker, NOW is an indicator of present time. The substitution test can also be used here. NOW as used in examples 1, 2, 3 above can be substituted with another time reference lexical item such as TODAY, AT THIS TIME and the sentences will remain grammatical. If we do a reverse substitution for example replacing temporal NOW with a discourse marker NOW we will get ungrammatical sentences.

Though it is difficult to distinguish the two uses of NOW as a discourse marker and as a temporal marker, Roy's [27] distributional and formal criteria can help in bringing out this distinction.

- The temporal form of NOW can occur at utterance initial position but without topic marking and neither is it accompanied by prior pauses.

- The discourse marker NOW appears utterances initial position. It is normally preceded by long pauses before the articulation of the sign.

Apart from the long pauses before the articulation of the sign, in KSL, this discourse marker $\mathrm{NOW}$ is also accompanied by Non-Manual grammatical markers (NGM). NGM also known as Non-manual signs are used to show grammatical information such as question markers, negation or affirmation, topicalization and sometimes for emphasis. For the sign NOW, the NGM that accompany it include widened eyes and wrinkled forehead. NOW as a discourse marker which our primary concern in this paper, is used to indicate a shift into a new topic or sub-topic. It is also used for calling attention to what is coming next in the text. In this way then NOW the discourse marker serves a cohesive function.

Apart from NOW, there are several other transitional markers used in KSL that also indicate a shift to the next topic or subtopic. These include:

\section{THATASIDE, MOVE/GO, FINISH}

\section{THAT ASIDE:}

In KSL THAT ASIDE is signed with two capped hand forms (at the knuckles) facing down in front of signer moving to the sides as illustrated below:

This sign appears only in the utterance-initial position to show that the topic or subtopic under discussion has ended and the "speaker" is embarking on a new topic or subtopic. For instance:

Fig.2.

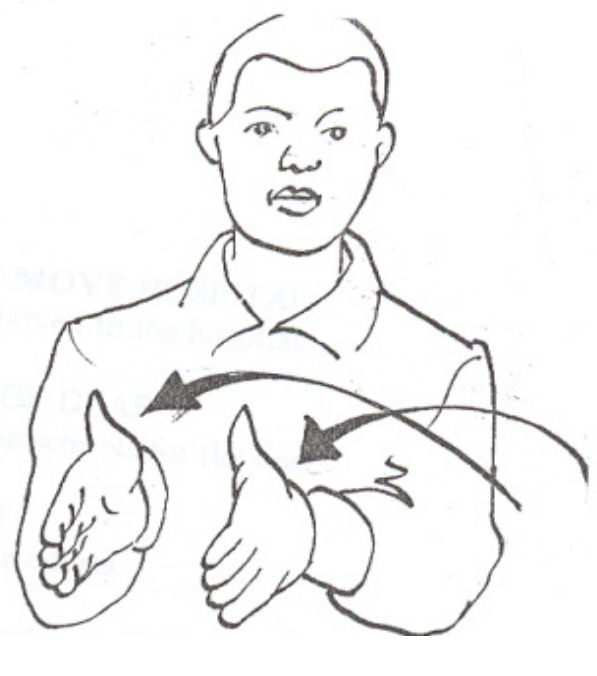

THAT ASIDE

\section{TIME DISCUSSION LONG}

After a long discussion FINISH/PEOPLE ALL TOGETHER everybody agreed to work together WORK ACCEPT // THAT ASIDE

And apart from that

PEOPLE ALL LUNCH

They all went for lunch

TOGETHER EAT//

together

The sign THAT ASIDE marks a transition from the first topic under discussion - the people discussing and agreeing to work together to the next that is having lunch together. As a discourse marker THAT ASIDE is used to indicate a shift into a new topic or sub-topic. Like NOW above, it is also used for calling attention to what is coming next in the text. In this way the discourse marker serves a cohesive function

\section{MOVE/GO}

MOVE /GO in KSL are also used to indicate a change of topic. It is signed with a B-hand form facing down bent at knuckles with all fingers touching at the thumb moving from front of signer to the side as illustrated below: 
Fig.3.

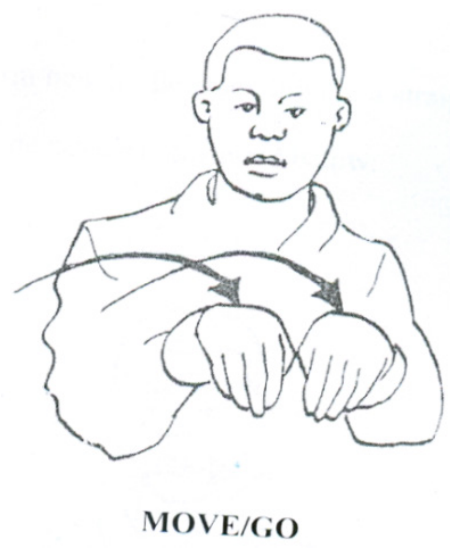

Examples:

\section{SECOND WE MOVE HOSPITAL//}

Secondly, we moved to the hospital.

In 5 above, MOVE is used with SECOND to indicate the transition is from first sub-topic to the second subtopic. Closely related to the sign MOVE is the sign GO. In KSL, GO can be used as a transition marker marking a shift to the next point to be discussed. Example:

\section{SO WE GO DEAF ASSOCIATION//}

And then we moved to the deaf associations.

GO here has the same use as MOVE meaning there is a shift from whatever was being discussed to the deaf association. Both these signs in KSL serve cohesive function since they link what has been said to what is going to be said next.

\section{FINISH}

FINISH is signed with arm bent at the elbow giving a straight B-hand form moving from one side of the mouth to the next, as illustrated below:

Fig.4.

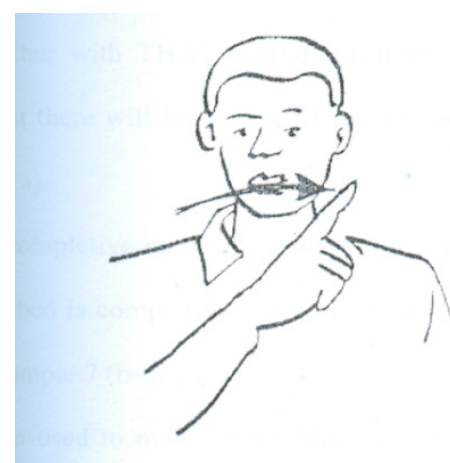

FINISH

The use of FINISH which Akach [28] calls an auxiliary verb in KSL is three fold in KSL.

1. It is used together with THAT ASIDE to show the end of a topic/subject under discussion and that there will be change of topic/subject. It is thus used as a discourse marker. For example:

\section{THE POLICE ACCEPTED WELL}

The police accepted very well to continue SAME NOW CONTINUE TOGETHER / to work with us in our research in POLICE BOTH RESEARCH WORKAREA the area of the police. POLICE FINISH/ THAT ASIDE//

That's all. That aside....

Its use here is similar to AFTER THAT/ THEN

b) It is used as "completive marker" Valli and Lucas [29] to show that the event being described is completely finished this is the perfective use of the auxiliary verb FINISH. For example:

\section{ME EAT FINISH//}

I have finished eating or I have already eaten.

a) FINISH is also used to mark finality and is synonymous to "that's all" in English. FINISH normally appears utterance final in all instances of usage.

Example.

\section{TEACHER SAY ME OLD FINISH//}

The teacher said I am old that's all.

\subsection{Signalers that Introduce New Items in a Time Series}

In a KSL lecture, there is also the use of several cohesive features to relate different cohesive relationships such as those that show the ties that exist within the text in terms of time and sequential or chronological relationships. The following time adjuncts and chronological signalers are used in the KSL: NOW, THEN, BEFORE, AFTER, TIME

Some of these cohesive features are used both as time adjuncts and chronological signalers. As time adjuncts they specify time reference of action. As chronological signalers, they are used to denote temporal sequence.

Example:

\section{0 a) SECOND SEMINAR COME}

A second seminar came but the situation SITUATION SAME TEACHING SIGN was the same we taught sign language. LANGUAGE/ LONG TIME CONTINUE After a long time of doing the same thing, NOW SWEDEN THINK IF WE

Sweden thought it was not good enough. TEACH SIGN LANGUAGE BUT to teach sign language without research WITHOUT RESEARCH GOOD NOTHING//

on the language itself.

b) WE START FEW TEACHERS/ AFTER 
We started with a few teachers

NORAD SUPPORT SIGN

but afterwards NORAD supported

LANGUAGE PROJECT WITH MONEY//

the sign Language project with funds.

c) NOW TEACHER START SHARING

Now the teachers started using both. They

BOTH/ START BOTH SHARING/

started to use both .Before then they were

BEFORE NOTHING NOW USE BOTH//

using neither but now they are using both.

d) FOR EXAMPLE BEFORE WE HAVE

For example along time ago

TELEPHONE//

we had the telephone.

e) BUT AFTER SEEING DIFFERENT

But when they saw different

HAND MOVEMENTS TELL START

hand movements confusion started.

CONFUSION//

f) TIME GO CATCH JOB FINISH. BUT

At the time they go look for a job problems

TIME INTERVIEW START PROBLEM//

begin during the time of interview.

g) TIME AFTER RESEARCH FOUND

After we did our research we

PERSON TRUE DEAF//

found it was true the person was deaf.

One unique characteristic of language is its ability to enable its users to communicate about events and entities that are remote in time and space. Language allows users to 'refer to the past, the future and non-immediate situation; it is not restricted to the present and the immediate". Valli and Lucas [30]. This feature of language is referred to as displacement. C.f. Yule [31]. Sign language makes use of time lines to communicate about events and entities that are remote in time and space. Time lines are viewed as metaphorical representation of time. In KSL, time or tense marking is represented by a time line that runs from the shoulder either behind or in front the person who is signing. From the shoulders to the space behind the signer is used to mark past tense and the further back, one indicates, the more distant one places the past action/event. This time line can be used to mark from past to remote past.

The time line in front of the signer is used to indicate present tense (very near the signer as NOW) and future tense. If the past is not specific enough, or has no time adverb such as LAST WEEK, YESTERDAY etc, then one only signs PAST. The time lines as used in KSL can be illustrated below:

Fig.5.

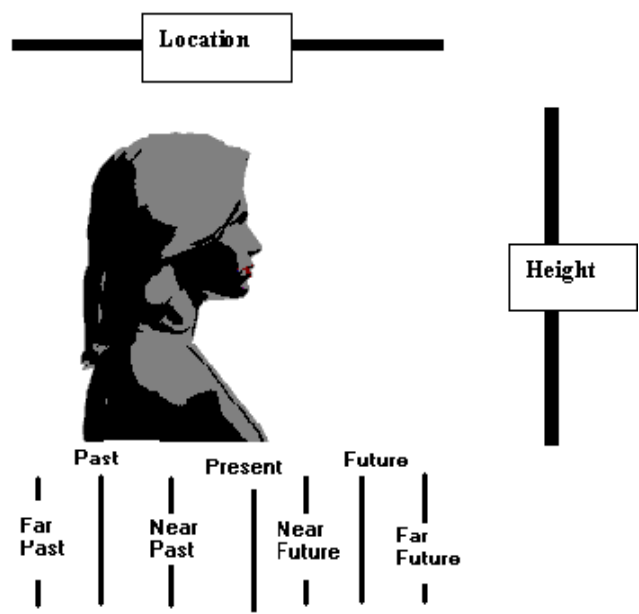

It is important to note that time and tense are not always the same since time adverbials can be used to mark time sometimes. The issue as to whether KSL has tense as a grammatical category is not dealt with exhaustively in this paper and thus the term tense is used in a loose sense.

The temporal markers in KSL mentioned above are exemplified in $10(\mathrm{a})-(\mathrm{g})$, NOW is used to denote a point in time. In 10 (a) it is used to indicate the point in time at which the Swedes decided that research in KSL was also important apart from just teaching the language. The use of NOW here is similar to that of NOW as an indicator of present time which should be distinguished from that of NOW as a new topic transitional marker as exemplified in 1 (a) - (f). AFTER as used in 10 (b) expresses forward directionality in which the earlier event "starting with a few teachers", provides the reason for the later one that is "NORAD supporting the project with money." In this way, AFTER is synonymous to afterwards, later etc in English. In 10 (e), the forward directionality is evident in the use of AFTER. Again here, an earlier event - "seeing different hand forms" provides reason for a later one - "confusion." In 10 (g) also AFTER serves the same function. The "research" provides purpose for finding that the person was really deaf. AFTER is signed as illustrated below:

Fig.6.

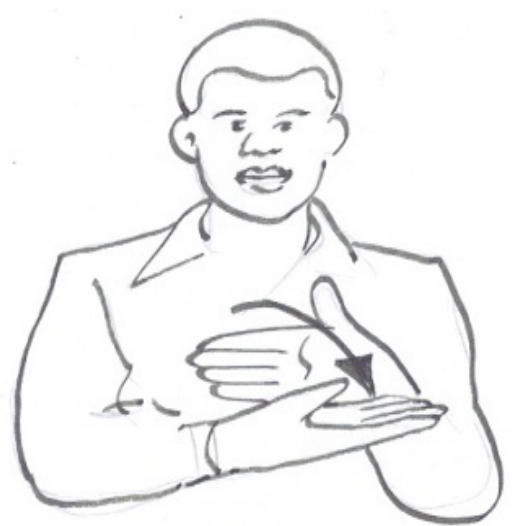

AFTER 
BEFORE is signed as follows:

Fig.7

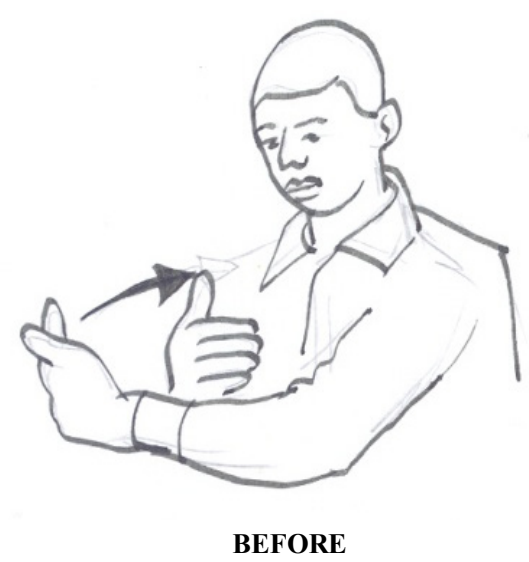

BEFORE, provides information on past events. It gives details of the circumstances about past time. In (d), BEFORE is used to compare past events - the availability of telephone, vis-à-vis the availability of the fax machine presently. In (c), BEFORE is used to show that in the past teachers used nothing (language of teaching) but presently they are using both (i.e. KSL and Oralism). In both cases BEFORE is used for backward directionality and also for temporal sub-ordination.

TIME is signed as exemplified below:

Fig. 8.

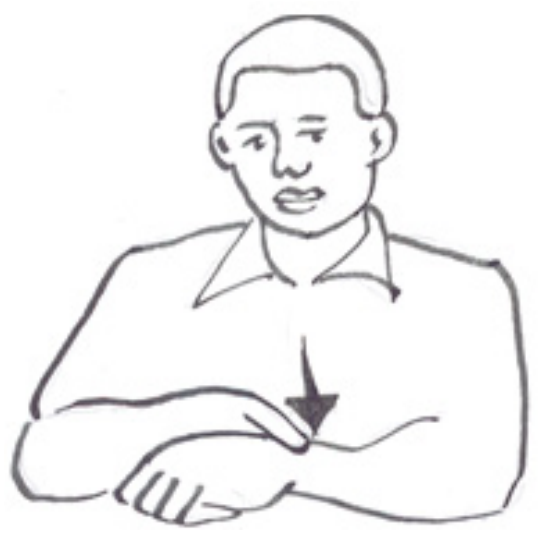

TIME

TIME is used as an equivalent of the adverb WHEN. Both TIME and WHEN can be used to refer to a sequence of past events. TIME denotes a point in time when something happened. In (f) it refers to the point in time when the deaf go looking for work. In $(\mathrm{g})$ it is used together with AFTER to refer to forward directionality in its meaning.

All the signs discussed above are cohesive features that relate different cohesive relationships. They are used to show the ties that exist within the text in terms of time and sequential relationships. In this way they link information in different ways. NOW for instance is used to indicate the point in time when something happened or as an indicator of present time. NOW can also be used as a new topic transitional marker in which case it links the old topic to the new topic. AFTER denotes forward directionality in that an earlier event provides reason for a later one. BEFORE on the other hand provides information on past events and is used to compare those evens, TIME refers to a point in time when something happened. All these signs in KSL operate within the time line. By linking information these signs server cohesive function.

\subsection{Chronological Signalers}

Chronological signalers or logical connectives are used to express specific types of relationships such as:

- Listing: This consists of signs that indicate additions or continuation. Those identified in KSL formal setting include; FIRST, SECOND, ONE, TWO etc. According to Crombie [32] "The relation of chronological sequences provides the semantic link between event propositions one which follows the other in time".

- Contrast: Crombie discusses this under matching relations asserting that: "it involves the comparison of two things, event or abstractions in terms of some particular in respect of which they are similar (simple comparison) or different (simple contrast)". Those identified in KSL include: BUT.

- Apposition: Two words, phrases or clauses are said to be in apposition when they have the same reference in a sentences. Apposition markers identified in KSL introduce the second unit and they include: FOR EXAMPLE and MEANING.

Examples:

\section{1 a) THIS RESEARCH PROJECT WENT}

The research project did research DIFFERENT AREAS /THIS START 1991

in different areas starting in 1991. We went GO DIFFERENT AREAS RESEARCH to different areas to research on what? WHAT?

NO.1 POLICE/

First the police.

NO.2 HOSPITAL RESEARCH/

Second we did research on hospitals. NO.3 PARENT RESEARCH/

Third we did research on parents of the deaf. NO. 4 SCHOOLS FOR THE DEAF Fourth we did research on schools for RESEARCH. / FIRST GO TO POLICE// the deaf. But we started with the police.

\section{b) NOW WE DECIDE WHAT? WE MUST}

Now what did we decide? We must do REACH PARENTS DEAF/ TWO research on parents of the deaf, secondly MUST PLAN SEMINAR HOSPITAL/ 
We must plan seminars for medical

THREE MUST PLAN SEMINAR

personnel and thirdly and seminars for

INTERESTED PEOPLE//

interested people.

\section{c) THIS INTERVIEW FINISH PICK}

After the interview we picked three people.

PICK PEOPLETHREE/ ONE,

One from Mombasa for the coast MOMBASA COAST REGION/ TWO

region. Secondly, another one from

OTHER CENTRAL NAIROBI, MERU

Central for the Nairobi, Meru and

AROUND THERE/ THREE OTHER KISII

surrounding region and thirdly,

BUT RESPONSIBLE KISUMU,

another for Kisii but also responsible for

KAKAMEGA//

Kisumu and Kakamega.

The signs for listing No. $1 \ldots 4$ or FIRST, TWO, THREE, in the examples above, are used to indicate additions or continuation of ideas and when used to indicate this they link earlier ideas to continuing ones. The linking is done anticipatorily because it occurs before the event and therefore they act as a preview of what is to follow. They also connect signs that indicate ideas in a series or list. These signs are made on the finger or using the fingers of the signer.

Following Liddel [33], we shall view the place where they are made as the Locus. A Locus being a point on the body or in the signing space that serves articulatory function. In this case, the locus also serves the referential equality function where we sign the numbers on the fingers e.g. No. 1 the finger used represents research done on the Police, (mostly the index finger in KSL) No. 2 (mostly the middle finger) Hospitals, No.3 (the ring finger) on Parents with deaf children, No.4 (the last finger) on Schools for the deaf. In serving the referential equality function, the locus refers to the different places that research was done.

The listing signs that chronologically link events are lexical signals. According to Hoey [34], lexical signalers may spell out a relation before, during or after the event. If it occurs before the event, it is termed anticipatory; if it occurs after the event it is termed retrospective. Whatever is being referred to by the signal is referred to as "lexical realization." Example (c) above is an example of anticipatory lexical signal.

In 11c) above, PICK PICK PEOPLE THREE anticipatorily signals what follows (or the lexical realization) which is enumeration. Thus the phrase PICK PICK PEOPLE THREE acts as preview for what follows. In 11 (a), also the signaling is anticipatory. WHAT acts as an anticipatory signal. However, in 11 (b) there is deletion of one of the lexical realization in that the connection to indicate ideas in a series does not start with ONE but gives the point represented by ONE and MOVES on straight to TWO and THREE.

\subsection{Signalers that Express Relations between}

1) facts.

In the lecture, there is also the use of lexical signals that express relations between facts. This is normally done through the use of conditionals. Conditionals indicate the consequences of something. Facts expressed in sentences sometimes determine or condition each other. Thus conditionals articulate a condition upon which the topic being discussed depends. As connectives, conditionals therefore express a dependency relationship between facts or propositions. The following is the KSL conditionals identified in the lecture: IF.

Examples:

\section{2a) MEANING IN FUTURE MAYBE IF}

In other words, if one TRY LEARN CONTINUOUSLY

tries to learn continuously it is MEANING POSSIBLE SUCCEED// possible to succeed.

\section{b) IF DEAF TRY SIGNING MEANING}

If the deaf try to use sign language that HIMSELF DEAF HAVE LANGUAGE means they have a language they can use SAME OTHER HEARING PEOPLE//

for communication just like the hearing people have their spoken language.

In 12 (a), (b), the conditional IF is used to show the interdependency nature of the facts in the sentences IF, therefore connects and relates the facts in the proposition. In 12 (a), IF states the dependency of one circumstance (in this case future success) on another (i.e. trying to learn continuously). Future success therefore depends on learning continuously. In 12 (a) there is a probable cause/ reason and probable consequences pattern - i.e. probable cause/reason trying to learn continuously - probable consequence possible success in future.

In 12 (b), IF also expressed the contingent dependence of one circumstance upon another. Here, the realization that the deaf have a language just like the hearing people is dependent on the deaf themselves signing or using it. In KSL, IF can appear either utterance initial or utterance medial in both cases it occurs as a sequence forming connective.

\subsection{Signalers that Introduce Items in the Same Series}

Other lexical signalers in the text introduce other items in the same series. Those identified in the text include: AGAIN and SAME as illustrated in fig. 9 below: 
Fig.9.
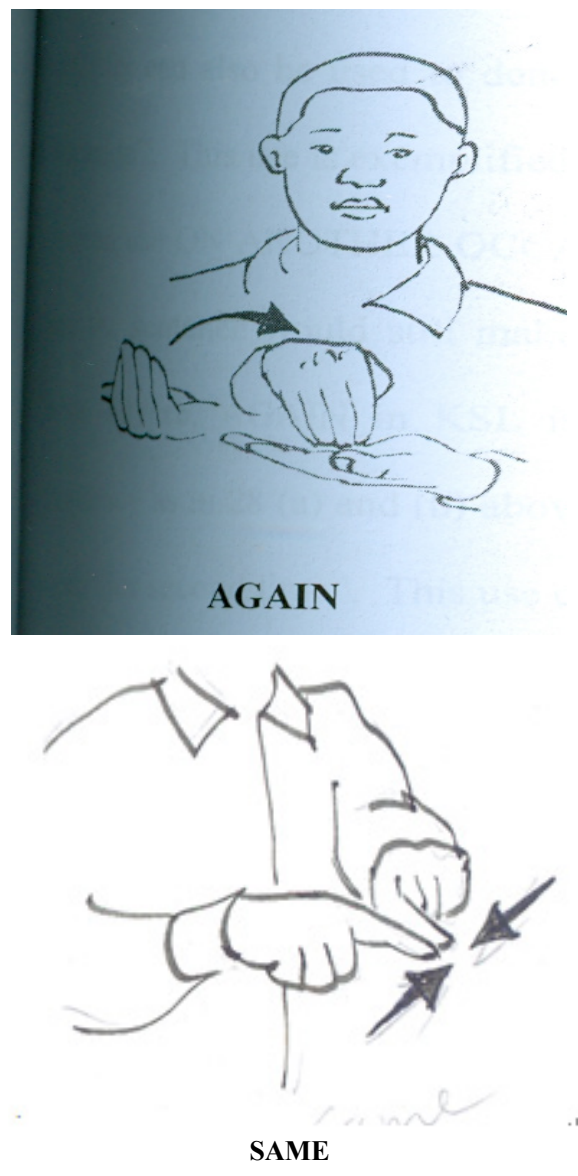

AGAIN in KSL is used as an additive adjunct, while SAME is used for comparative reference.

Examples:

\section{BUT AFTER LEARNING ENGLISH}

But why do deaf people forget their LEARN KISWAHILI/ BUT WHY DEAF first language later after they learn English THROW FIRST LANGUAGE? AGAIN and learn Kiswahili? Also the deaf are MUST LEARN ENGLISH /BUT SIGN expected to learn English even though they LANGUAGE DON'T KNOW BASIC BIG

Don't even understand even basic sign QUESTION//

language.

AGAIN as used above in 13 comes subsequent to the focused part of the utterance. In all the three instances, the first part is the focused part of the utterance and the information that comes after AGAIN is an addition to the first part of the proposition.

AGAIN can also be used to denote a point in time or as an equivalent to "on another occasion" in English. This use is exemplified above in 13. Using a substitution criteria, we can use ON ANOTHER OCCASION in the place of AGAIN in 13 above and the sentence would still make complete senses. AGAIN is thus used as a time - when adverb. AGAIN in
KSL is also used to show frequency particularly definite frequency as in 13 above. This way AGAIN functions as a number adverb to mean "for second time". This use comes out clearly in 13 above.

In KSL, SAME as a lexical signaler is used for comparative reference. It denotes that a certain noun phrase is referentially equivalent to a previous or preceding one. SAME therefore is used for anaphoric or cataphoric reference. Examples:

\section{4 a) TIME JUDGE HIMSELF GIVE}

The judge gave us the name of the NAME PERSON BUT WE GO SEE interpreter. We went to see him PERSON TRUE/ BUT PERSON SAME

But he was too drunk.

DRINK TOO MUCH//

b) THESE PEOPLE FROM

People from Kakamega

KAKAMEGA KNOW THIS PERSON

will know that this is a person from.

FROM MARAGOLI /SAME THESE

Maragoli. Similarly, the

KAKAMEGA THEMSELVES KNOW

Kakamega people themselves know.

In 14 (a) above, SAME is co-referenced to the Noun phrase PERSON which appears before it thus giving it anaphoric reference. In 14 (b), SAME is co-referenced to THESE KAKAMEGA, which appears after it thus giving it cataphoric reference. SAME above is mostly used for emphatic purposes. It puts emphasis on the NP, it is co-referenced to. Thus SAME can appear pre or post the focused part.

Sometimes when SAME appears before the focused part, it still serves the additive function only, and it is also used as an equivalent of similarly in English as shown in the following examples:

15c) SAME ME GIVE GROUP

Similarly, I gave the group an attachment

ATTACHMENT GO SCHOOL DEAF

to go visit schools for the deaf and find out

SEE INSIDE COMMUNICATION HOW?

how the deaf communicate among themselves.

In $15 \mathrm{c}$ ) above, SAME is used to refer to the subsequent part of the utterance giving it cataphoric reference.

\subsection{Signalers that show Quantity}

Quantifiers are used in KSL for lexical cohesion since they denote certain relationship between lexical items in an utterance. Quantifiers are amount sign or signs that denote quantity or amount. Quantifier signs identified in KSL formal discourse include:

\section{MORE, FEW, ZERO, NOTHING, and MANY.}

These amount signs are generally signed in KSL as illustrated in fig 10 below: 
Fig.10.

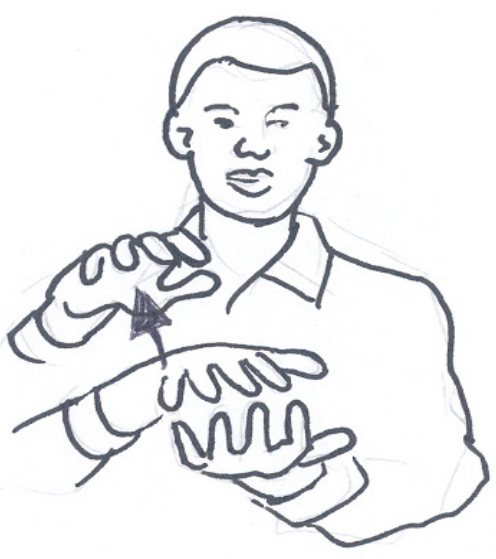

MORE

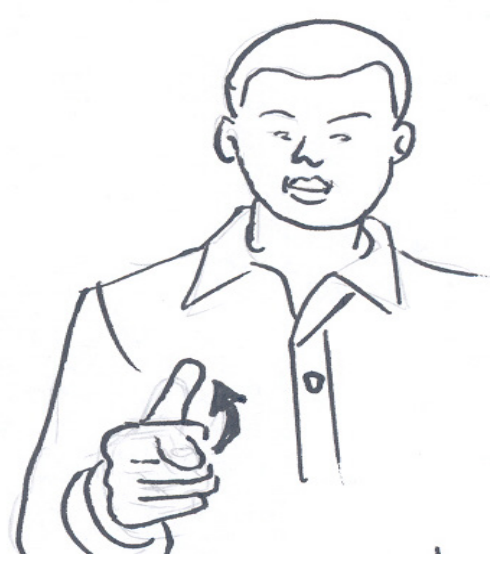

FEW

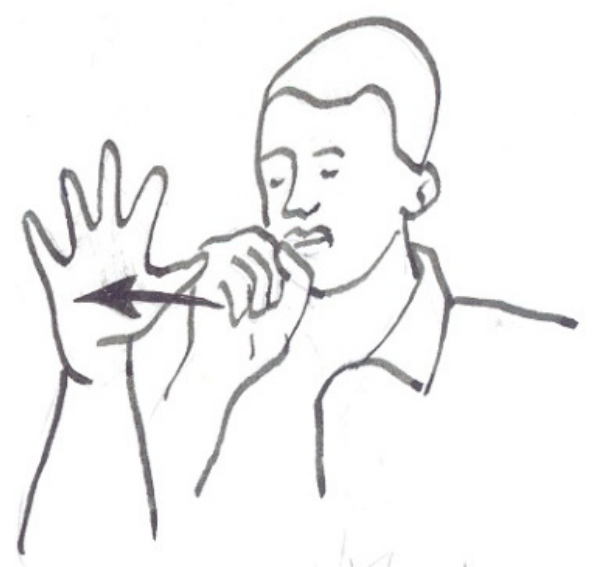

NOTHING

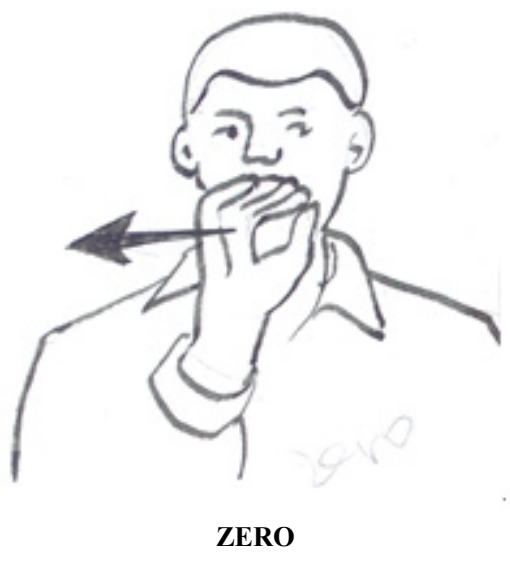

Examples:

16(a) WE START FEW TEACHERS

We started off with a few teachers later /AFTER NORAD SUPPORT SIGN NORAD assisted the project with funds LANGUAGE WITH MONEY WE thus enabling us to call CALLED MORE// more teachers. b) THIS SITUATION BIG CHALLENGE/ This was a big challenge since when TIME THAT SAME KSL SIGNING the deaf were using Kenya sign language INSPECTOR UNDERSTAND The inspector of schools did not NOTHING//

understand anything. c) TWO, CALL TEACHERS COME Secondly, we called teachers of the deaf TEACH SIGN LANGUAGE CALL/ to teach them Kenyan sign language, we PEOPLE INTERESTED LEARN SIGN We also called interested people to LANGUAGE COME TEACH SIGN come and learn the language we called LANGUAGE OTHER/ LEARN SIGN Many many different people to come LANGUAGE DIFFERENT MANY and learn Kenyan sign language MANY PEOPLE BUSINESS LEARN including business people. People have SIGN LANGUAGE UP TO NOW// been learning the language up to today.

FEW as used in 16 (a) above is a negative quantifier since it expresses negative meaning about the noun it is quantifying that is TEACHERS. FEW thus co-occur with countable nouns to mean "not many". 
NOTHING in 16 (b) is also a negative sign. In KSL it normally appears in proposition final position. It is produced using an "O" hand form from the month moving to a neutral position ending in a spread B-hand form (see Illustration fig 10 above). In 16 (b) it is used to mean that the school inspectors themselves do not understand KSL.

MORE and MANY are used for comparative numerative purpose as quantifiers. They refer to indefinite quantity. They function as amplifiers or boosters in the utterances they appear in. In KSL, they appear in utterances medial position and are used with countable nouns in 16 (c) PEOPLE and in 16 (a) TEACHERS. MORE and MANY have cataphoric reference since they refer to the subsequent in an utterance. In 16 (a) however, MORE has anaphoric reference since it is co-indexed to TEACHERS.

\subsection{Signalers that Introduce Examples or Particularization of What Has Just Been Said}

Lexical cohesion in KSL formal situations is also brought out through the use of logical connections such as apposition. Apposition is the situation where two or more nominal phrases occur next to each other and refer to the same person or thing. The apposition noted in the KSL lecture is non-restrictive apposition that uses expressions that explicitly indicate apposition. These indicators express certain semantic information between the appositives. (Cf. Quirk and Greenbaum, [35]; Hoey, [36]. The lecture makes use of explicit apposition, which is made explicit by adverbial phrases such as "for example". Exemplification in KSL can also manifest itself in clues that enumeration follows. In exemplification two or more members are used where the first member provides a general statement and the second adds one or more propositions used as exemplification of the general statement in the first member. FOR EXAMPLE is signed as illustrated in fig 11 below:

Fig.11.

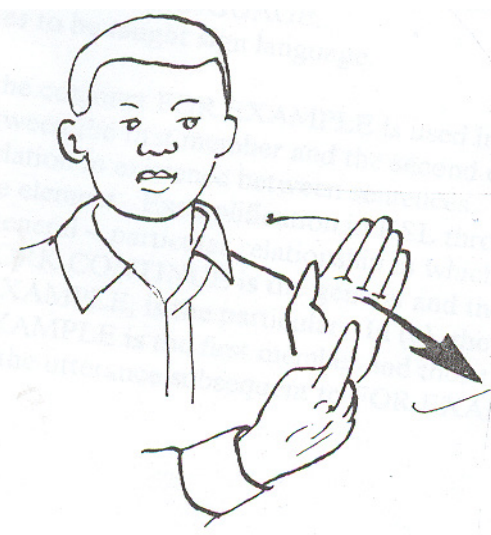

FOR EXAMPLE

Examples:

17 a) THIS DEAF CATCH

When a deaf person is employed

WORKTRYWORK CONTINUE FOR they try their best to work.

EXAMPLE TRUE WORK THERE

For example, it is possible for them to POSSIBLE AGREE WORK THERE// agree to work anywhere.

b) FOR EXAMPLE IF YOU SPEAK

For example if you speak Kiswahili KISWAHILI OTHER FRENCH OR and others speak French or Japanese JAPANESE COME LIKE TEACH YOU

And the Japanese comes and would HIMSELF USE JAPANESE

like to teach you Japanese CONTINUOUSLY//

all the time.

c) THIS PROJECT START 1991/ GO

This project was started in 1991 and DIFFERENT AREAS RESEARCH what different areas did we do WHAT?

research in?

NO.1 POLICE RESEARCH/ NO. 2

Firstly, we did research at the police station, HOSPITAL RESEARCH/ NO.3 PARENTS Secondly, at the hospitals, thirdly parents RESEARCH/ NO.4 SCHOOLS FOR THE With deaf children and fourthly, schools DEAF RESEARCH/ FOUR AREAS// for the deaf, these four main areas. d) THIS INTERVIEW FINISH PICK After the interview, we picked three

PICK PEOPLE THREE /ONE

people. One for Mombasa and the

MOMBASA COAST REGION/ TWO coast region, the second one for Nairobi,

OTHERCENTRAL, NAIROBI MERU

Central, Meru and surrounding areas AROUND OTHER/ THREE OTHER KISII

The third one was for Kisii but was BUT RESPONSIBLE KISUMU, also responsible for Kisumu and KAKAMEGA//

Kakamega.

In the examples above, the conjunct FOR EXAMPLE is used in 17(a) and 17(b). It is used to indicate a co-relation between the first member and the second one in the proposition. It shows the interlocking relation in existence between sentences. Exemplification in this case is used as an additive element. Exemplification in KSL through the conjunct FOR EXAMPLE expresses a general- particular relationship in which in (a) THE DEAF CATCH WORK TRYWORK CONTINUE is the general and the rest of the sentence, which also include FOR EXAMPLE, is the particular.

When the first member gives a generalized proposition as 
is the case in 17(a), the relationship that exists between the first and the second member is one of the matching compatibility. The example introduced by the conjunct FOR EXAMPLE in the above sentences, is part of the evidence for generalization found in the first member. Thus in 17(a) the conjunct FOR EXAMPLE is used to clarify the general statement in the first member or proposition. In 17(a), the conjunct FOR EXAMPLE appear in the utterance medial position. In 17(b) the conjunct FOR EXAMPLE appears in utterance initial position in this example the first member is omitted but the context in which the exemplification takes place assists the listener to understand the utterance.

17(c) and (d) above exemplify another type of general-particular relationship which Hoey calls preview detail relation. In this type of relation exemplification mainly manifests itself in the form of a clue for following listing. In 17(d) for instance "PICK PICK PEOPLE THREE" acts as a clue that enumeration follows. This clue acts as a signaling word for clarification to follow. In 17(c) the sign clarification follows signaling sign is WHAT. This question word in KSL helps one predict that some clarification will follow.

\subsubsection{Signalers that indicate a restatement of what has just} been said:

Another important signaling devices used in KSL, is repetition.

\section{Examples:}

18a) PROBLEM SAME SAME/

The problem is that all the deaf people

ALLCONGREGATE NAIROBI HERE/

congregate in Nairobi. When they come to

TIME CONGREGATE NAIROBI MEET

Nairobi they come in contact with many

MEET FRIENDS DEAF//

other deaf people.

b) THIS WHY FLY BACK? TOGETHER

Why did they come back? They wanted to

COOPERATE DEAF KENYA/ TIME

work together with deaf Kenyans.

CONTINUE TOGETHER DEAF

this cooperation with deaf Kenyans led to

KENYANS HERE HERE START KNAD

the establishment of Kenya National Association

1987 DECEMBER//

Association of the Deaf in December 1987.

c) THESE WAZUNGU TWO WAZUNGU

These two white Volunteers were both

VOLUNTEERS BOTH MARRY

deaf and they were married to

BOTH DEAF//

each other.

d) THESE MEANING DEAF THESE

This meant that the deaf themselves had

MUST TEACH THIS PERSON

to teach this person Kenyan sign

LANGUAGETHIS/ UNDERSTAND THIS language meaning that the person

MEANING LEARN SECOND

had to learn a second

LANGUAGE//

language.

e) TEACHERS THEMSELVES LEARN,

The teachers learnt, argued

ARGUE ASK QUESTIONS/ BUT

among themselves and asked questions.

THEMSELVES FIRST BASIC LEARN

They also agreed they needed to

TELL YES MUST FIRST

first learn and understand basic

LANGUAGE KSL KNOW//

Kenyan sign language.

f) NOW TEACHERS START SHARING

Now the teachers started using both sign

BOTH START SHARING BEFORE

language and oralism. Before this they were

NOTHING NOW USE BOTH//

not using both but now they started using both.

The repetition of SAME in 18 (a) above is for rhetoric emphasis since the speaker wants to make very clear the sameness of the problem. The same can be said about the repetition of MEET MEET in 18 (a) HERE HERE in 18(b). In this use, the lexical item repeated follows the one that precede it immediately.

In 18(a), the lexical item CONGREGATE is repeated, in 18 (b) TOGETHER is also repeated so is WAZUNGU in 18 (c) and also BOTH in 18 (c), THIS in 18 (d), THEMSELVES in 18 (e) START, BOTH and SHARING in 18 (f). All these are examples of simple repetition where a lexical item that appeared previously is subsequently repeated mostly for emphatic purposes.

In 18(c), we can note an instance of complex repetition. TWO is a complex repetition of THESE it can be regarded as a paraphrase of THESE. Repetition is significant in signaling matching and general particular relations. In 18 (c), THESE and TWO are matched for similarity and thus their relation is one of matched compatibility.

In 18 (d), the repetition of THIS represents an element of both ellipsis and substitution. The third THIS in the utterance serves as a substitute for the deleted phrases Kenyan sign language - LANGUAGE THIS is KSL. The fourth THIS substitutes a phrase that does not appear - teaching the person KSL. With the repetition of THIS, the structure appears incomplete however; the missing elements are recoverable from previous statements.

In 18 (e) THEMSELVES is repeated. This repetition exemplifies ellipsis and substitution. The second THEMSELVES is a substitute for TEACHERS which has been deleted. In 18 (e) an occurrence of accidental repetition can be observed. The repetition of the lexical element FIRST. The second FIRST is not co-referenced to the first at all nor is there any discernable relation between the two. The initial FIRST is used to mean number one it is thus used for 
enumeration while the second FIRST refers to language one.

18 (f) is an example of repetition know as parallelism where a combination of words is repeated, the phrases may contain identical phraseology. Its use introduces balance in sentences. Parallelism points out the correspondence between the related clause or neighbouring clauses of different meaning. In 18 (f) START SHARING BOTH/START BOTH SHARING.

The parallelism in this utterance has double information focus for purposes of emphasis. The nucleus is on START the theme of the clause. The other focus is on the terminal part of the second clause that is SHARING. Parallelism is important for emphasis and conciseness due to its involving phrasing of important ideas in the same grammatical form thus making repetition rhythmic. In 18 (f), there is also repetition of other elements such as BOTH which exemplify simple repetition.

\section{Conclusions}

The lecture discussed in this paper, is structurally organized through the various episodes- i.e. the focal, developmental and closing episodes each of which also have several obligatory and optional episodes these episodes are used to structure content. However, apart from this structural organization, content in the lecture is also structured through textual features that reflect the transitional boundaries between episodes and in the process link episodes together as discussed above. The words and phrases used this way are cohesive and therefore contribute to the listener's ability to make sense of the text or contribute to the texts cohesion.

From our discussion above, it is apparent that people have different languages they use but even these languages are used differently. Certain variables come into play that determine the formality or informality of language use. This situation thus gives rise to language varieties that are characteristic of social situations or register Finegan [37]

Different registers have characteristic language features thus for example "casual talk "or informal register will significantly differ from a lecture or sermon which are formal.

Formality or plannedness is an aspect of style and thus the term style can be used to refer to varying level of formality of each of the different register. Registers can range on a continuous scale of formality from high level variety e.g. University lecture to low level register such as casual conversation.

The lecture in KSL under analysis was given by a deaf person to a group of University students. The speaker is a native KSL user while the audience was mostly "seeing" KSL in use for the first time. There was therefore a KSL interpreter who facilitated communication between the speaker and his audience. The lecture tended to be more formal given the situational factors in plays that have to match with the formality of language in relation to the addressee and the addresser.
Due to the formality of the lecture situation, the language used was also formal. Thus language used was context reduced. Participants normally do not have an abundance of situation and paralinguistic cues at their disposal. Richards et al assert: paralinguistic features include the use of non vocal phenomena such as facial expression head or eye movement and gestures. These may add support, emphasis, or particular shades of meaning to what people are saying. In KSL however, all these features described by Richards et al (op. cit) as paralinguistic features are actually part of the linguistics of the language. Thus vocal phenomenon in KSL is part of its paralinguistic features since SL is visualgestural.

The formality of KSL determines the type of lexical signalers or textual features that are not only used organizationally in KSL but also guide the listener on how to interpret information that they are hearing. They also “... contribute to a listeners ability to distinguish between major and minor points, old versus new information, turns and shifts in the flow of the topic" Roy. This way of structuring discourse is known as cohesion. The following cohesion devices were discussed in this paper: New topic transition markers, Signalers that introduce new items in the time series, Chronological signalers, Signalers that express relations between facts, Signalers that introduce items in the same series, Quantity signalers, Signalers that introduce example or particularization of what has just been said and Signalers that indicate a restatement of what has just been said (repetition).

\section{REFERENCES}

[1] Stokoe, W. C. Sign Language structure: An outline of the Visual Communication System of American deaf. Studies in Linguistics Occasional paper 8. University of Buffalo. 1960.

[2] De Saussure, F. Course in General Linguistics.1916.

[3] Roy, C. B. Features of discourse in an American Sign Language lecture, in Lucas, C. (ed.) the Sociolinguistics of the Deaf Community. California Academic Press Inc.: California. 1989.

[4] Lucas, C. (ed.) The sociolinguistics of the Deaf community. California Academic Press Inc.: California. 1989.

[5] Kavangah J. F. and Cuttings E.S. (eds.) The role of speech in language. Cambridge: MIT Press. (1975).

[6] Siegmund, P and Vollhaber, T. Current Trends in European Sign Language Research: proceedings of the third European Congress on Sign Language Research. Hamburg. 1993

[7] Ochs, E.K. and Bennett, T. Discourse Across Time and Space. Department of Linguistics, University of Carlifornia. 1977.

[8] Akach, P. A. O. Sentences types in Kenyan Sign Language. Unpublished M.A diss. University of Nairobi. 1991.

[9] Mweri, J. G. Kenyan Sign Language Dictionary. Kenyan 
Sign Language Research project. Nairobi: 2000

[10] [10] Okombo Okoth, "Obstacles in the development of African Sign Languages"; Proceedings of East African Sign Language Seminar. 1990 "Linguistics and the Liberation of the Kenyan Deaf: Research Agenda for Sign Language Developers"; in proceedings of East African Sign Language Seminar.1990 "African Languages: Will sign Language have better luck? "Bilingualism in the schools for the Deaf." In Proceedings of the XI World Congress of the World Federation of the Deaf.1994.

[11] Okombo, O. \& Akach, P.A.O. Language convergence and wave phenomenon in the growth of a national Sign Language in Kenya, in Abdulaziz (ed.) International Journal of the Sociology of Language. No. 125: New York: Mount de Grutyter p. 31. 1997.

[12] Mweri, G. J. "Diversity in Education; Kenyan sign Language as a medium of Instruction in schools for deaf in Kenya." Springeropen Journal. 2014.www.multilingual-edu cation.com/content/4/1/14.

[13] Halliday, M. A. K. and Hasan, R. Cohesion in English. London: Edward Arnold.1976.

[14] Halliday, M.A.K. Dimensions of Discourse Analysis: Grammar. In T. Van Dijk (ed). A Handbook of Discourse Analysis. London: Academic Press.Vol.2, pp. 29-56. 1985.

[15] Joss, M. The isolation of style. In readings in the sociology of language, ed. J. Fishman. The Hague; Mouton. 1968.

[16] Crystal, D. \& Davy, D. Investigating English style. Bloomington: Indian University Press. 1969.

[17] Ferguson, C.A. Diaglossia. In Word. Journal of the linguistic code of New York. New York international linguistics Association. 1959.

[18] Fischer, Susan D. More than just hand waving: the mutual contributions of sign language and linguistics. The signs of language revisited: an anthology to honor Ursula Bellugi and Edward Klima. Edited by Emmorey and Harlan Lane. NJ: Lawrence Erlbaum Associates, pp195-213. 2000.

[19] Halliday, M.A.K. Dimensions of Discourse Analysis: Grammar. In T. Van Dijk (ed). A Handbook of Discourse Analysis. London: Academic Press.Vol.2, pp. 29-56. 1985.

[20] Quirk, R., S. Leech, Svartvik, J. A comprehensive grammar of the English language. London: Longman.1985.

[21] Richards, J et al Longman dictionary of Applied linguistics. London: Longman.1987.

[22] Joss, M. The isolation of style. In readings in the sociology of language, ed. J. Fishman. The Hague; Mouton. 1968.

[23] Cook, G. Discourse and literature, Oxford: Oxford University Press. 1994

[24] Roy, C. B. Features of discourse in an American Sign Language lecture, in Lucas, C. (ed.) the Sociolinguistics of the Deaf Community. California Academic Press Inc.: California.1989.

[25] Halliday, M.A.K. Dimensions of Discourse Analysis: Grammar. In T. Van Dijk (ed). A Handbook of Discourse Analysis. London: Academic Press.Vol.2, pp. 29-56. 1985.

[26] Roy, C. B. Features of discourse in an American Sign Language lecture, in Lucas, C. (ed.) the Sociolinguistics of the Deaf Community. California Academic Press Inc.: California. 1989.

[27] Roy, C. B. Features of discourse in an American Sign Language lecture, in Lucas, C. (ed.) the Sociolinguistics of the Deaf Community. California Academic Press Inc.: California. 1989.

[28] Akach, P. A. O Sentences types in Kenyan Sign Language. Unpublished M.A diss. University of Nairobi.1991.

[29] Valli, C \& Lucas, C. Linguistics of American Sign Language: An introduction (2 $2^{\text {nd }}$ Ed.) Washington DC: Gallaudet University Press. 1995

[30] Valli, C \& Lucas, C. Linguistics of American Sign Language: An introduction (2 $2^{\text {nd }}$ Ed.) Washington DC: Gallaudet University Press. 1995

[31] Yule, G. The Study of language. CUP. 2006.

[32] Crombie, W. Discourse and language learning: A relational approach to syllabus design. Oxford: Oxford University Press. 1985

[33] Liddle, S.K. Spatial representation in discourse: contemporary spoken and signed languages. Elsevier science B.V. 1996.

[34] Hoey, M. On the Surface of Discourse. London: Edward Arnold.1983.

[35] Quirk. R and Greenbaum, S. A University Grammar of English, Pearson Education. 2004.

[36] Hoey, M. On the surface of discourse. London: Edward Arnold.1983.

[37] Finegan, E. Language its structure and use. Harcourt Brace. 2004. 